\title{
Advanced breast cancer
}

\author{
An update to systemic therapy
}

Emma Carson, Rachel Dear

\section{Background}

Breast cancer is the most common cancer in women in Australia. Breast cancer is a heterogeneous disease; subtypes are defined by their biology with prognostic and therapeutic implications. Advancements in treatment have led to improved survival and quality of life for patients with advanced breast cancer.

\section{Objective}

The aim of this article is to provide a concise update regarding the current systemic management of advanced breast cancer, including novel treatment options.

\section{Discussion}

The aim of treatment in advanced breast cancer is to prolong life, manage symptoms and improve quality of life. The general practitioner is an important member of the patient's multi-disciplinary team.
BREAST CANCER is the most common cancer affecting women in Australia, with one in eight women being diagnosed by the age of 85 years. ${ }^{1}$ In 2018, it was estimated that 18,235 new cases of breast cancer would be diagnosed $(18,087$ in women and 148 in men). ${ }^{1}$ It is also the second most common cause of cancer death in women, after lung cancer. ${ }^{1}$

Curable early stage breast cancer involves disease localised to the breast and local lymph nodes. Advanced breast cancer includes both locally advanced disease not curable with surgery and metastatic breast cancer with distant metastases in other organs, commonly bone, lung, brain and liver. ${ }^{2}$ Approximately $20-30 \%$ of early stage disease will relapse with distant metastatic disease. ${ }^{3}$

Although advanced breast cancer is not curable, treatments can help prolong life, manage symptoms and improve quality of life. Potential benefits of treatment must be outweighed by the associated toxicity. Treatment is continued until there is evidence of disease progression or the patient develops unacceptable toxicity. Research has improved our understanding of breast cancer subtypes, treatment resistance and prognostic biomarkers and has led to the discovery of novel targeted therapies. The general practitioner (GP) is an important team member for women in the community living with advanced breast cancer.

\section{Signs and symptoms}

Signs and symptoms depend on the site of metastatic disease along with tumour burden. Many women are asymptomatic and may not develop symptoms for many years. Any new or worsening symptom reported to the GP or oncologist should prompt further assessment. Common signs, symptoms and appropriate investigations are listed in Table 1.

\section{Management}

Breast cancer is a heterogeneous disease, with subtypes defined by their biology with prognostic and therapeutic implications. The choice of therapy depends on the tumour biology, clinical factors such as sites of metastatic disease, cancer symptoms, age, comorbidities, performance status and patient preferences.

Subtypes include hormone receptorpositive $(\mathrm{HR}+)$, human epidermal growth factor receptor 2-positive (HER2+) and triple negative breast cancer. HER2+ breast cancer can be either $\mathrm{HR}+$ or hormone receptor-negative. Subtypes are explained in Table 2.

Endocrine therapy is used for HR+ breast cancer. ${ }^{4,5}$ HER2-directed therapy is used for HER2+ breast cancer. ${ }^{4,5}$ Chemotherapy is used for hormone receptor-negative breast cancer and $\mathrm{HR}+$ breast cancer that has become resistant to endocrine therapy. ${ }^{4,5}$ Clinical trials are appropriate for patients with good performance status who have exhausted standard treatment options, or to allow access to novel therapies. Treatment options for advanced breast cancer are listed in Table 3.

\section{Endocrine therapy}

For post-menopausal women, endocrine options include aromatase inhibitors, tamoxifen and fulvestrant. Aromatase 
inhibitors inhibit the aromatase enzyme and prevent oestrogen synthesis. They include letrozole, anastrozole and exemestane, all taken as a daily tablet. ${ }^{6-8}$ Common side effects include fatigue, arthralgias, hot flushes, fluid retention, vaginal dryness and bone density loss. Tamoxifen is a selective oestrogen receptor modulator (SERM) with mixed oestrogen receptor antagonist activity in breast cancer and breast tissue, while also an oestrogen receptor agonist in bone and the uterus, explaining why bone density may improve and why tamoxifen is associated with an increased risk of endometrial cancer. Common side effects include fatigue, hot flushes, mood changes and fluid retention; rare side effects include increased risk of venous thromboembolism and endometrial carcinoma. Fulvestrant is a selective oestrogen receptor degrader (SERD) given as a monthly intramuscular injection. ${ }^{9}$ Fulvestrant is not listed on the Pharmaceutical Benefits Scheme (PBS) and is obtained through a cost share program, whereby the patient and drug company share the cost. Side effects include injection site reactions, hot flushes and arthralgias.

For pre-menopausal women, options include tamoxifen or ovarian suppression in combination with tamoxifen or an aromatase inhibitor. Ovarian suppression is achieved by monthly gonadotrophin releasing hormone agonist injections such as goserelin, or by surgical bilateral salpingoophrectomy. ${ }^{10}$

\section{Targeted therapy}

Everolimus is a mechanistic target of rapamycin inhibitor taken orally daily together with exemestane for HR+ disease. Side effects include fatigue, mucositis and diarrhoea. ${ }^{11}$

\begin{tabular}{lll}
\hline \multicolumn{2}{l}{ Table 1. Signs, symptoms and investigations for advanced breast cancer } \\
\hline Metastatic site & Signs and symptoms & Investigations \\
\hline General & Fatigue, depression, anxiety & FBC \\
\hline Bone & $\begin{array}{l}\text { Pain, hypercalcaemia, } \\
\text { pathological fracture }\end{array}$ & $\begin{array}{l}\text { Serum calcium and ALP, plain } \\
\text { X-rays, whole-body bone scan }\end{array}$ \\
\hline Liver & $\begin{array}{l}\text { Jaundice, ascites, } \\
\text { coagulopathies }\end{array}$ & LFTs, USS/CT abdomen \\
\hline Lung & $\begin{array}{l}\text { Dyspnoea, cough, haemoptysis, } \\
\text { pleuritic chest pain }\end{array}$ & Chest X-ray, CT chest \\
\hline $\begin{array}{l}\text { CNS (brain, spinal } \\
\text { cord, leptomeningeal } \\
\text { disease) }\end{array}$ & $\begin{array}{l}\text { Headache, cognitive } \\
\text { impairment, motor or sensory } \\
\text { loss, seizures }\end{array}$ & \begin{tabular}{l} 
CT/MRI brain, MRI spinal cord \\
\hline Lymph nodes
\end{tabular} \\
$\begin{array}{ll}\text { Brachial plexopathies, pain } \\
\text { Clinical examination of cervical } \\
\text { and supraclavicular lymph } \\
\text { nodes, USS }\end{array}$
\end{tabular}

$A L P$, alkaline phosphatase; $C N S$, central nervous system; CT, computed tomography; $F B C$, full blood count; LFT, liver function test; MRI, magnetic resonance imaging; USS, ultrasound scan

Table 2. Molecular subtypes of breast cancer

\begin{tabular}{lccc}
\hline $\begin{array}{l}\text { Breast cancer } \\
\text { molecular subtype }\end{array}$ & Oestrogen receptor & $\begin{array}{c}\text { Progesterone } \\
\text { receptor }\end{array}$ & HER2 receptor \\
\hline $\begin{array}{l}\text { Hormone receptor- } \\
\text { positive }\end{array}$ & + & $+/-$ & - \\
\hline HER2-positive & $+/-$ & $+/-$ & + \\
\hline Triple negative & - & - & - \\
\hline
\end{tabular}

HER2-directed agents include trastuzumab, pertuzumab, trastuzumab emtansine (T-DM1) and lapatinib. Trastuzumab and pertuzumab are humanised monoclonal antibodies to the HER2 receptor, given intravenously every three weeks. ${ }^{12,13}$ Trastuzumab can also be given subcutaneously. Both are generally well tolerated; cardiotoxicity is a rare but serious side effect, and therefore patients require regular echocardiograms or gated heart pool scans. T-DM1 is an antibodydrug conjugate given intravenously every three weeks; side effects include cytopaenias and cardiotoxicity. ${ }^{14}$ Lapatinib is a tyrosine kinase inhibitor taken orally daily in combination with oral capecitabine chemotherapy. ${ }^{15}$ Side effects include diarrhoea, hand-foot syndrome, fatigue, nausea, vomiting and rashes.

The cyclin-dependent kinases (CDK) $4 / 6$ inhibitors are a promising new class of agents used to treat advanced breast cancer. Clinical trials have shown that the combination therapy of CDK4/6 inhibitors, with endocrine therapy for advanced $\mathrm{HR}+$ disease, improves progression-free survival when compared with endocrine therapy alone; overall survival data are not yet available and require longer follow-up. There are three drugs in this class that have similar efficacy in the first-line and second-line setting but are at different stages of availability in Australia. Side effects include fatigue, anaemia, neutropaenia, thrombocytopaenia and diarrhoea. Despite neutropaenia being common, it is manageable with dose delays and reductions; febrile neutropaenia is also rare.

Ribociclib was PBS listed as of July 2018 for the first-line treatment of advanced HR+ breast cancer. ${ }^{16}$ It is taken orally daily in combination with an aromatase inhibitor for three weeks, and then followed by a one-week break. Electrocardiogram monitoring is recommended, as ribociclib is associated with prolonged QT syndrome. Palbociclib is another CDK4/6 inhibitor that was approved by the Therapeutic Goods Administration in May 2017 as first-line treatment in combination with an aromatase inhibitor, ${ }^{17}$ or second-line treatment in combination 
with fulvestrant. ${ }^{18}$ Palbociclib is also taken orally daily for three weeks with a one-week break. As of 1 October 2018, palbociclib can be accessed through a cost share program arranged by the oncologist. A third CDK4/6 inhibitor, abemaciclib, is taken in combination with letrozole ${ }^{19}$ or fulvestrant. ${ }^{20}$ It is taken by continuous oral daily dosing. It causes more diarrhoea than the other two agents and is the only drug that shows single-agent activity in heavily pre-treated patients. ${ }^{21}$ Abemaciclib may be accessed through clinical trials or a compassionate access program arranged by the oncologist.

Olaparib is a poly(adenosine diphosphate-ribose) polymerase (PARP) inhibitor that delays disease progression for germline BRCA mutant breast cancer. ${ }^{22}$ It is not yet PBS listed for breast cancer but is available by compassionate access from the drug company. It is taken orally daily, and side effects include fatigue, anaemia, gastrointestinal upset and increased risk of myelodysplastic syndrome. An advantage of olaparib is that it can delay the need for chemotherapy.

\section{Chemotherapy}

Single-agent chemotherapy is preferable to combination chemotherapy in the palliative setting, because of fewer side effects and better quality of life. ${ }^{23}$ There is no evidence demonstrating an overall survival benefit with combination therapy. Combination chemotherapy may be considered in patients with rapidly progressive disease or large tumour burden affecting organ function. Single-agent intravenous options include taxanes (paclitaxel, nab-paclitaxel, docetaxel), doxorubicin, eribulin and vinorelbine; oral options include capecitabine and vinorelbine.

\section{Triple negative breast cancer}

Triple negative breast cancer is hormone receptor-negative and HER2 receptornegative. It is associated with locoregional recurrence, lung and brain metastases and a poorer prognosis. Chemotherapy is

Table 3. Treatment options for advanced breast cancer

\begin{tabular}{|c|c|c|c|}
\hline Drug name & Indication & Drug type & Adverse effects \\
\hline Tamoxifen & $\begin{array}{l}\text { Hormone receptor- } \\
\text { positive }\end{array}$ & $\begin{array}{l}\text { Selective oestrogen receptor } \\
\text { modulator }\end{array}$ & $\begin{array}{l}\text { Fatigue, hot flushes, mood changes, } \\
\text { fluid retention, endometrial cancer } \\
\text { (rare), VTE (rare) }\end{array}$ \\
\hline Everolimus & $\begin{array}{l}\text { Hormone receptor- } \\
\text { positive }\end{array}$ & $\begin{array}{l}\text { Mechanistic target of rapamycin } \\
\text { inhibitor }\end{array}$ & Fatigue, mucositis, Gl upset, diarrhoea \\
\hline Fulvestrant & $\begin{array}{l}\text { Hormone receptor- } \\
\text { positive }\end{array}$ & $\begin{array}{l}\text { Selective oestrogen receptor } \\
\text { degrader }\end{array}$ & $\begin{array}{l}\text { Injection site reactions, hot flushes, } \\
\text { arthralgias }\end{array}$ \\
\hline Trastuzumab emtansine & HER2-positive & Antibody-drug conjugate & $\begin{array}{l}\text { Anaemia, thrombocytopaenia, } \\
\text { peripheral neuropathy, cardiotoxicity } \\
\text { (rare) }\end{array}$ \\
\hline Lapatinib & HER2-positive & Tyrosine kinase inhibitor & $\begin{array}{l}\text { Diarrhoea, hand-foot syndrome, fatigue, } \\
\text { nausea, vomiting, rashes, cardiotoxicity } \\
\text { (rare) }\end{array}$ \\
\hline $\begin{array}{l}\text { Ribociclib, palbociclib, } \\
\text { abemaciclib }\end{array}$ & $\begin{array}{l}\text { Hormone receptor- } \\
\text { positive }\end{array}$ & CDK 4/6 inhibitor & $\begin{array}{l}\text { Fatigue, anaemia, neutropaenia, } \\
\text { thrombocytopaenia, mucositis, } \\
\text { diarrhoea, prolonged QT }\end{array}$ \\
\hline
\end{tabular}


the mainstay of treatment, as endocrine therapy and HER2-directed therapies are ineffective. It has been shown to be more immunogenic, and so clinical trials are in ongoing investigation of immunotherapy either alone or in combination with chemotherapy. Immunotherapy appears to be more beneficial given earlier in the treatment course. The best way for patients to access immunotherapy is through participation in a clinical trial. A recent phase 3 trial, with atezolizumab (PD-L1 checkpoint inhibitor) in combination with nab-paclitaxel chemotherapy as first-line treatment for advanced triple negative breast cancer, demonstrated significantly improved progression-free survival and encouraging overall survival results. ${ }^{24}$ Antibody-drug conjugates, such as sacituzumab, are also being investigated in this subtype.

\section{Local management options}

Systemic therapy is the mainstay of treatment for advanced breast cancer; however, local management of the primary or metastases may be indicated to provide local control and improve quality of life. For example, a fungating or ulcerated breast primary may be treated with radiotherapy or surgery. Spinal cord compression from vertebral bony metastases should be managed with radiotherapy and/or surgical decompression. A symptomatic malignant pleural effusion should be managed with a pleural drain; a talc pleurodesis can help prevent recurrence. Brain metastases should be treated with corticosteroids to reduce oedema and whole brain radiotherapy. Select cases may be considered for more definitive treatment options such as stereotactic body radiotherapy or surgical resection.

\section{Management of bone metastases}

Patients with bone metastases should be commenced on an osteoclast inhibitor, either zolendronic acid $4 \mathrm{mg}$ intravenous monthly or denosumab 120 mg injection monthly. They reduce skeletal-related events, including fractures, the need for bone surgery or radiotherapy, spinal cord compression and malignancy-related hypercalcaemia. ${ }^{25,26}$ Symptomatic painful bony metastases can be managed effectively with radiotherapy.

\section{Prognosis}

The median survival for advanced breast cancer is two years, but with a wide range from months to many years. Survival varies depending on tumour subtype, sites and burden of metastatic disease, along with the patient's performance status. The median survival for $\mathrm{HR}+$ disease is 79 months, ${ }^{27}$ HER2+ disease 56 months ${ }^{28}$ and triple negative disease 12 months. ${ }^{29}$ From 1985 to 2016, the five-year survival rate has improved from $10 \%$ to $27 \%$. ${ }^{30}$ The introduction of trastuzumab in 2000 has been the most significant treatment discovery for breast cancer. ${ }^{12}$ Factors indicating favourable prognosis include $\mathrm{HR}+$ disease, prolonged relapse-free interval from early stage disease of $\geq 2$ years and metastases to bone, chest wall or nodes. Poor prognostic factors include young age of $<35$ years at diagnosis, triple negative disease, brain or liver metastases and lymphangitis carcinomatosis of the lung.

\section{Monitoring}

Patients should have clinical reviews every 3-6 months; blood tests including full blood count, urea electrolytes and creatinine, liver function test, comprehensive metabolic panel, cancer antigen (CA) 15.3 tumour marker (occasionally correlates with disease progression and treatment response); and imaging including computed tomography (CT) chest, abdomen, pelvis and bone scan. Positron emission tomography scans are currently not funded for advanced breast cancer, but are scheduled to receive Medicare Benefits Schedule (MBS) funding from November 2019. Reviews continue until the patient's end of life; frequency may be increased or decreased depending on symptoms or disease progression.

\section{Multidisciplinary team}

A large multidisciplinary team is required to comprehensively meet the medical and psychosocial needs of a patient living with advanced breast cancer. This team may consist of a medical oncologist, radiation oncologist, palliative care physician, GP, breast cancer nurse, palliative care nurse and a clinical psychologist. Palliative care services provide a holistic approach to manage symptoms, improve quality of life and plan for end-of-life care; early involvement is recommended.

\section{CASE}

Jane, a woman aged 61 years, presented to her GP with a one-month history of increasing shortness of breath, left shoulder pain, back pain and a $6 \mathrm{~cm}$ fungating left breast lesion that had been present for many years. She was visibly unwell with respiratory distress and appeared slightly confused. Her GP referred her straight to a local emergency department for further assessment and acute management.

Jane's past medical history included hypertension, hypercholesterolaemia and type 2 diabetes mellitus. She was separated and lived at home alone, with two daughters living nearby.

Blood tests demonstrated hypercalcaemia with a corrected calcium level of $4.55 \mathrm{mmol} / \mathrm{L}$. A CT pulmonary angiogram demonstrated bilateral pulmonary emboli and destructive bony lesions in both clavicles, left scapula and multiple ribs. A staging CT chest, abdomen and pelvis and whole-body bone scan demonstrated diffuse skeletal metastatic deposits and pathological vertebral fractures of $\mathrm{T} 5$ and $\mathrm{T} 12$. A biopsy of the breast lesion confirmed a grade 2 invasive ductal carcinoma, which was oestrogen receptor-positive and progesterone receptor-positive and HER2 receptor-negative.

A diagnosis of advanced HR+ breast carcinoma was made, complicated by malignant hypercalcaemia secondary to diffuse bony metastases and pulmonary emboli. Jane commenced letrozole $2.5 \mathrm{mg}$ daily and the PBS-reimbursed CDK 4/6 inhibitor ribociclib $600 \mathrm{mg}$, which is taken for 21 out of every 28 days. She received palliative radiotherapy to the fungating breast lesion as well as to 
her painful left shoulder and thoracic spine. Pain from her bone disease was managed with oxycodone slow-release $20 \mathrm{mg}$ twice daily, with oxycodone $5 \mathrm{mg}$ as required for breakthrough pain relief. Her pulmonary emboli were treated with therapeutic enoxaparin, and the hypercalcaemia improved with intravenous fluids, calcitonin and zolendronic acid.

After discharge, Jane was seen regularly by her GP, who managed her analgesia. Her bony pain improved after the radiotherapy and so her GP titrated down the oxycodone, eventually ceasing it altogether. She commenced denosumab $120 \mathrm{mg}$ injections for the bony metastases, which she continues to receive monthly with her GP. Through the MBS Chronic Disease Management scheme, Jane received MBS-funded psychology services, helping her come to terms with her diagnosis. Her GP also continues to manage her other comorbidities, including her hypertension, hypercholesterolaemia and diabetes.

At Jane's oncology follow-up appointment eight weeks after diagnosis, the breast lesion had decreased in size and her CA 15.3 tumour maker had decreased from $1500 \mathrm{U} / \mathrm{mL}$ at diagnosis to $80 \mathrm{U} / \mathrm{mL}$. Repeat staging CT and bone scan demonstrated stable bony metastases with sclerosis (indicating treatment effect) and no new lesions. Her neutrophils were low at $0.9 \times 10^{9} / \mathrm{L}$, which is a common side effect from CDK4/6 inhibitors, and consequently the dose of ribociclib was decreased to $400 \mathrm{mg}$.

During Jane's admission, her oncologist had explained to her and her family that she now had incurable advanced breast cancer with an average prognosis of two years, but that those with $\mathrm{HR}+$ disease may live up to six years. Advanced care planning for end of life was advised. Jane visited her GP to discuss this further. After a discussion about her goals and wishes for terminal care, she decided she would like to die in a hospice, as she did not want to burden her family. She signed an advanced care plan with goals including comfort measures and no cardiopulmonary resuscitation. Her daughters were informed of this plan.

Currently Jane is well and asymptomatic from her cancer. She feels fatigued from the treatment, but her quality of life is good and she recently enjoyed a holiday with her daughters and grandchildren in Queensland.

\section{Key points}

- Breast cancer is a heterogeneous disease, with subtypes defined by their biology with prognostic and therapeutic implications.

- Treatment advancements have led to improved survival and quality of life.

- Treatment options include endocrine therapy, targeted therapy, chemotherapy, radiotherapy and osteoclast inhibitors for bony metastases.

- Immunotherapy is a promising option for advanced triple negative disease.

- A multidisciplinary team approach is required to comprehensively meet the patient's medical and psychosocial needs.

\section{Authors}

Emma Carson MB, BCh, BAO, Medical Oncology advanced trainee, Kinghorn Cancer Centre, St Vincent's Hospital, Darlinghurst, NSW; Conjoint Associate Lecturer, Sydney Medical School, University of New South Wales, NSW. emmakate. carson@health.nsw.gov.au

Rachel Dear MBBS, FRACP, PhD, Medical Oncologist, Kinghorn Cancer Centre, St Vincent's Hospital, Darlinghurst, NSW; Sydney Medical School, University of Sydney, Chris O'Brien Lifehouse, Camperdown, NSW

Competing interests: None.

Funding: None.

Provenance and peer review: Not commissioned, externally peer reviewed.

\section{References}

1. Cancer Australia. Breast cancer statistics. Surry Hills, NSW: Cancer Australia, 2018. Available at https://breast-cancer.canceraustralia.gov.au/ statistics [Accessed 24 March 2019].

2. Patanaphan $\vee$, Salazar OM, Risco R. Breast Cancer: Metastatic patterns and their prognosis. South Med J 1988;81(9):1109-12.

3. Peto R, Davies C, Godwin J, et al. Comparisons between different polychemotherapy regimens for early breast cancer: Meta-analyses of longterm outcome among 100,000 women in 123 randomised trials. Lancet 2012;379:32-44. doi: 10.1016/S0140-6736(11)61625-5.
4. Cardoso F, Costa A, Senkus E, et al. 3rd ESOESMO international consensus guidelines for advanced breast cancer (ABC 3). Anna Oncol 2017;28(1):16-33. doi: 10.1093/annonc/mdw544.

5. National Comprehensive Cancer Network. NCCN guidelines for patients: Breast cancer noninvasive. Plymouth Meeting, PA: NCCN, 2018. Available at www.nccn.org/patients/guidelines/content/PDF/ stage_0_breast.pdf [Accessed 24 March 2019].

6. Mouridsen H, Gershanovich M, Sun Y, et al. Superior efficacy of letrozole versus tamoxifen as first-line therapy for postmenopausal women with advanced breast cancer: Results of a phase III study of the International Letrozole Breast Cancer Group. J Clin Oncol 2001;19(10):2596-606. doi: 10.1200/JCO.2001.19.10.2596.

7. Bonneterre J, Buzdar A, Nabholtz JM, et al. Anastrozole is superior to tamoxifen as first-line therapy in hormone receptor positive advanced breast carcinoma. Cancer 2001;92(9):2247-58.

8. Kaufmann M, Bajetta E, Dirix L, et al. Exemestane is superior to megestrol acetate after tamoxifen failure in postmenopausal women with advanced breast cancer: Results of a phase III randomized double-blind trial. The Exemestane Study Group. J Clin Oncol 2000;18(7):1399-411. doi: 10.1200/ JCO.2000.18.7.1399.

9. Chia S, Gradishar W, Mauriac LY, et al. Doubleblind, randomized placebo controlled trial of fulvestrant compared with exemestane after prior nonsteroidal aromatase inhibitor therapy in postmenopausal women with hormone receptorpositive, advanced breast cancer: Results from EFECT. J Clin Oncol 2008;26(10):1664-70. doi: 10.1200/JCO.2007.13.5822.

10. Taylor CW. Green S, Dalton WS, et al. Multicenter randomized clinical trial of goserelin versus surgical ovariectomy in premenopausal patients with receptor-positive metastatic breast cancer: An intergroup study. J Clin Oncol 1998;16(3):994-99. doi: 10.1200/JCO.1998.16.3.994.

11. Yardley DA, Noguchi S, Pritchard KI, et al. Everolimus plus exemestane in postmenopausal patients with $\mathrm{HR}(+)$ breast cancer: BOLERO-2 final progression-free survival analysis. Adv Ther 2013;30(10):870-84. doi: 10.1007/s12325-0130060-1.

12. Slamon DJ, Leyland-Jones B, Shak S, et al. Use of chemotherapy plus a monoclonal antibody against HER2 for metastatic breast cancer that overexpresses HER2. N Engl J Med 2001;344(11):783-92.

13. Dang C, lyengar N, Datko F, et al. Phase II study of paclitaxel given once per week along with trastuzumab and pertuzumab in patients with human epidermal growth factor receptor 2-positive metastatic breast cancer. J Clin Oncol 2015;33(5):442-47. doi: 10.1200/JCO.2014.57.1745.

14. Krop IE, Kim SB, González-Martín A, et al. Trastuzumab emtansine versus treatment of physician's choice for pretreated HER2positive advanced breast cancer (TH3RESA): A randomised, open-label, phase 3 trial. Lancet Oncol 2014;15(7):689-99. doi: 10.1016/S14702045(14)70178-0.

15. Geyer CE, Forster J, Lindquist D, et al. Lapatinib plus capecitabine for HER2positive advanced breast cancer. N Engl J Med 2006;355(26):2733-43. doi: 10.1056/ NEJMoa064320.

16. Hortobagyi GN, Stemmer SM, Burris HA, et al. Ribociclib as first-line therapy for HR-positive, advanced breast cancer. N Engl J Med 2016;375(18):1738-48. 
17. Finn RS, Martin M, Rugo HS, et al. Palbociclib and letrozole in advanced breast cancer. N Engl J Med 2016;375(20):1925-36.

18. Cristofanilli M, Turner NC, Bondarenko I, et al. Fulvestrant plus palbociclib versus fulvestrant plus placebo for treatment of hormone-receptorpositive, HER2-negative metastatic breast cancer that progressed on previous endocrine therapy (PALOMA-3): Final analysis of the multicentre, double-blind, phase 3 randomised controlled trial. Lancet Oncol 2016;17(4):425-39. doi: 10.1016/ S1470-2045(15)00613-0.

19. Goetz M Jr, Toi M, Campone M, et al. MONARCH 3: Abemaciclib as initial therapy for advanced breast cancer. J Clin Oncol 2017;35(32):3638-46. doi: 10.1200/JCO.2017.75.6155.

20. Sledge GW, Toi M, Neven $P$, et al. MONARCH 2 : Abemaciclib in combination with fulvestrant in women with $\mathrm{HR}+/ \mathrm{HER} 2-$ advanced breast cancer who had progressed while receiving endocrine therapy. J Clin Oncol 2017;35(25):2875-84. doi: 10.1200/JCO.2017.73.7585.

21. Dickler MN, Tolaney SM, Rugo HS, et al. MONARCH 1, a phase II study of abemaciclib, a CDK4 and CDK6 inhibitor, as a single agent, in patients with refractory HR+/HER2metastatic breast cancer. Clinical Cancer Res 2017;23(17):5218-24. doi: 10.1158/1078-0432.CCR17-0754.

22. Robson M, Seock-Ah I, Senkus E, et al. Olaparib for metastatic breast cancer in patients with a germline BRCA mutation. N Engl J Med 2017;377:523-33. doi: 10.1056/NEJMoa1706450.

23. Dear RF, McGeechan K, Jenkins MC, Barratt A, Tattersall MHN, Wilcken N. Combination versus sequential single agent chemotherapy for metastatic breast cancer. Cochrane Database of Syst Rev 2013;(12):CD008792. doi: 10.1002/14651858.CD008792.pub2.
24. Schmid P, Adams S, Rugo HS, et al. Atezolizumab and nab-paclitaxel in advanced triple negative breast cancer. N Engl J Med 2018;379(22):2108-21. doi: 10.1056/NEJMoa1809615.

25. Lipton A, Fizazi K, Stopeck AT, et al. Superiority of denosumab to zoledronic acid for prevention of skeletal-related events: A combined analysis of 3 pivotal, randomised, phase 3 trials. Eur J Cancer 2012;48(16):3082-92. doi: 10.1016/j. ejca.2012.08.002.

26. O'Carrigan $B$, Wong MHF, Willson ML, Stockler MR, Pavlakis N, Goodwin A. Bisphosphonates and other bone agents for breast cancer. Cochrane Database Syst Rev 2017;10:(CD003474). doi: 10.1002/14651858. CD003474.pub4.

27. Savci-Heijink CD, Halfwerk H, Hooijer GKJ Horlings HM, Wesseling J, van de Vijver MJ. Retrospective analysis of metastatic behaviour of breast cancer subtypes. Breast Cancer Res Treat 2015;150(3):547-57. doi: 10.1007/s10549-015 3352-0.

28. Swain SM, Baselga J, Kim SB, et al. Pertuzumab, trastuzumab, and docetaxel in HER2-positive metastatic breast Cancer. N Engl J Med 2015;372:724-34. doi: 10.1056/NEJMoa1413513.

29. Tutt $A$, Tovey $H$, Cheang MCU, et al. Carboplatin in BRCA1/2-mutated and triple-negative breast cancer BRCAness subgroups: The TNT trial. Nat Med 2018;24:628-37. doi: 10.1038/s41591-0180009-7.

30. Sundquist M, Brudin L, Tejler G. Improved survival in metastatic breast cancer 1985-2016. Breast 2017:31;46-50. doi: 10.1016/j.breast.2016.10.005. 